\title{
Advances in the targeted therapy of liposarcoma
}

\author{
Zhonghai Guan' \\ Xiongfei Yu' \\ Haohao Wang' \\ Haiyong Wang' \\ Jing Zhang' \\ Guangliang $\mathrm{Li}^{2}$ \\ Jiang $\mathrm{CaO}^{3}$ \\ Lisong Teng'
}

'Department of Surgical Oncology, First Affiliated Hospital, College of Medicine, Zhejiang University, ${ }^{2}$ Department of Medicine Oncology, Zhejiang Cancer Hospital, ${ }^{3}$ Clinical Research Center, The 2nd Affiliated Hospital, School of Medicine, Zhejiang University, Hangzhou, Zhejiang,

People's Republic of China
Correspondence: Lisong Teng

Department of Surgical Oncology, First Affiliated Hospital, College of Medicine, Zhejiang University, 79 Qingchun Road, Hangzhou, Zhejiang 310003 , People's Republic of China Tel +86 57I 8706 8873;

$+8613666676918$

Fax +86 57I 87236628

Email Isteng@zju.edu.cn
This article was published in the following Dove Press journal:

OncoTargets and Therapy

5 January 2015

Number of times this article has been viewed
Abstract: Liposarcoma (LPS) is the most common type of soft-tissue sarcoma. Complete surgical resection is the only curative means for localized disease; however, both radiation and conventional cytotoxic chemotherapy remain controversial for metastatic or unresectable disease. An increasing number of trials with novel targeted therapy of LPS have provided encouraging data during recent years. This review will provide an overview of the advances in our understanding of LPS and summarize the results of recent trials with novel therapies targeting different genetic and molecular aberrations for different subtypes of LPS.

Keywords: well-/dedifferentiated, myxoid/round cell, pleomorphic, soft-tissue sarcoma

\section{Introduction}

Liposarcoma (LPS) is the most common type of soft-tissue sarcoma (STS), which consists of over 50 different malignancies of mesenchymal origin. ${ }^{1,2}$ According to the revised World Health Organization classification guideline published in early $2013,{ }^{3}$ almost 11 years after the previous edition, ${ }^{4}$ there are three different subtypes that are widely diverse in clinicopathological and molecular characteristics: well-/dedifferentiated (WD/DD) LPS, myxoid/round-cell (MRC) LPS, and pleomorphic LPS (PLS). Complete surgical resection is the only curative means for localized disease; however, both radiation and conventional cytotoxic chemotherapy remain controversial for metastatic or unresectable disease. ${ }^{5,6}$ Therefore, there is now an increasing demand for more effective systemic therapies. Targeted therapy of LPS has developed in recent years as a result of a better understanding of the molecular and genetic aberrations for each histologic subtype. ${ }^{7} \mathrm{WD} / \mathrm{DD}$ are the most common subtypes of LPS. ${ }^{1}$ WD is typically low grade, while DD is more aggressive. WD makes surgical resection challenging, owing to its occurrence most often in the deep soft tissues and to the high chance of local recurrence, which will often lead ultimately to dedifferentiation. ${ }^{8}$ Extremity WD LPSs always remain well differentiated and can be controlled by surgery with radiotherapy. ${ }^{9}$ DD has a approximately $15 \%-20 \%$ risk of distant metastasis and $\sim 30 \%$ 5-year survival rate. ${ }^{4}$ Treatment options other than surgery for both WD/DD are limited due to their resistance to conventional cytotoxic chemotherapy and radiotherapy. ${ }^{9}$ Although both tumor types exhibit the same amplification of chromosome 12q13-1 including the MDM2 gene, they have very different appearances pathologically. WD is characterized by adipocyte proliferation, while DD appears with both an adipocyte-rich WD portion and a fusiform-cell-rich DD portion. ${ }^{1}$ WD does not metastasize, but DD LPS has the potential for distant metastasis. Nearly $25 \%-40 \%$ of WD patients will ultimately manifest DD histology at recurrence. ${ }^{8}$ This phenomenon, namely, dedifferentiation, is a histologic form of tumor progression, which was also described as an extreme form of the epithelial-mesenchymal transition. ${ }^{10,11}$ It is still unclear how the process of dedifferentiation happens. MRC is the second most common subtype of LPS. Myxoid-cell LPSs, lacking round cell 
areas, are considered to be less aggressive tumors, with $\sim 90 \%$ 5 -year overall survival rate compared with $50 \%$ in round-cell LPS. ${ }^{12}$ Round-cell LPS is defined as a type of myxoid-cell LPS that has an associated round-cell component in $>5 \%$ of a given tumor. Round-cell transformation is related to more aggressive clinical behavior. ${ }^{13}$ MRCs are known for their sensitivity to cytotoxic chemotherapy ${ }^{14}$ and radiotherapy ${ }^{15}$ in comparison with the other LPS subtypes ${ }^{16}$ in patients with advanced or metastatic disease. Most MRCs consistently show a reciprocal translocation $\mathrm{t}(12 ; 16)(\mathrm{q} 13 ; \mathrm{p} 11.2)$, and less commonly, $\mathrm{t}(12 ; 22)$ (q13; 12 ), leading to FUS-CHOP fusion and EWS-CHOP fusion, respectively. ${ }^{17,18}$ Both are thought to interfere with normal adipocytic differentiation through $\mathrm{C} / \mathrm{EBP}$ and activate a number of tyrosine kinase receptor pathways including MET, RET, and PI3K/Akt. There are 12 different kinds of FUS-CHOP fusion transcripts detected to date, and they can be mainly classified into three categories: specifically, type I (exons 7-2), type II (exons 5-2), and type III (exons 8-2). ${ }^{19}$ The correlation between the types of fusion transcript and prognosis is not clear. ${ }^{13}$ Besides, four types of EWS-CHOP have been described, including exons 7-2 (type 1), exons 10-2 (type 2), exons 13-2 (type 3), and exons 13-3 (type 4), among which type 1 fusion might have a more favorable course. ${ }^{20}$ PLS is much more aggressive than the other LPS subtypes and is highly resistant to all current treatment modalities. ${ }^{21,22}$ It is the less frequent type with complex genomic gains and losses, which are similarly seen in poorly differentiated sarcomas. ${ }^{1}$

\section{Therapeutic targets of LPS Genetic amplification/overexpression}

\section{I2q 13-15 amplicon}

The hallmark genetic amplification of the 12q13-15 chromosomal interval in WD/DD implies an early and possibly critical event for LPS genesis. ${ }^{23}$ Therefore, genes included in this amplicon, which can be detected by molecular methods, such as Southern blotting, florescence, or chromogenic in situ hybridization, and by real-time quantitative polymerase chain reaction, ${ }^{24,25}$ are of major interest for their potential to serve as therapeutic targets. ${ }^{26}$

The MDM2 gene, also known as HDM2 in humans, located at $12 \mathrm{q} 15$, is consistently amplified in almost $100 \%$ of WD/DD. ${ }^{27,28}$ MDM2 amplification results in an inhibited p53 activity with loss of function of this tumor suppressor. ${ }^{29} \mathrm{P} 53$, which was identified in $1979^{30}$ as a transcription factor, binds to the promoter and increases expression of the $M D M 2$ gene. In turn, the MDM2 protein binds to p53 and diminishes its activity through multiple mechanisms: 1) MDM2 exports p53 out of the nucleus, 2) it directly inhibits the transactivation function of $\mathrm{p} 53$, and 3 ) it promotes proteosome-mediated degradation of p53 through its E3 ubiquitin ligase activity. ${ }^{31,32}$ Interestingly, $M D M 2$ can downregulate the levels of $E 2 F 1$ and $D P 1$ subunits by inducing degradation of the heterodimer. ${ }^{33}$ It has been reported that the exons 1 and 2 of $H M G A 2$, a gene located at $12 \mathrm{q} 14.3$ and known for being rearranged in ordinary lipomas, was consistently co-amplified with MDM2. ${ }^{26}$

Similar to $M D M 2$ and $H M G A 2$, cyclin dependent kinase-4 or $C D K 4$ is also amplified in $\sim 90 \%$ of cases of $\mathrm{WD} / \mathrm{DD}$, and represents another appealing therapeutic target. ${ }^{34}$ Mechanistically, $C D K 4$ phosphorylates and functionally inactivates the retinoblastoma $(\mathrm{Rb})$ protein and then uninhibits cell-cycle progression from the $\mathrm{G} 1$ to the $\mathrm{S}$ phase. ${ }^{35} C D K 4$ inhibition would thus restore native cell-cycle regulation and prevent uncontrolled tumor cell proliferation. However, $C D K 4$ is not present in $\sim 10 \%$ of cases. ${ }^{26}$ It was reported that the absence of $C D K 4$ amplification was not specifically counterbalanced by another genomic alteration, but may only represent a "MDM2-HMGA2-helper" in WD/DD tumorigenesis. In their study, Italiano et al observed that reduced expression of $R B 1$ was very frequent, independently of the $C D K 4$ status. $R B 1$ belongs to the $R B$ family, codes for the $\mathrm{pRb}$, which have pivotal roles in controlling fundamental cellular mechanisms such as cell cycle, differentiation, and apoptosis. ${ }^{36} \mathrm{It}$, therefore, appears that targeting the $\mathrm{Rb}$ oncoprotein deregulation in WD/DD might be a potential intervention approach. ${ }^{9}$

YEATS4, a transcription factor involved in p53 regulation, ${ }^{37,38}$ is frequently co-amplified with MDM2 and HMGA2. ${ }^{19}$ Using large-scale genomic analysis of multiple STS types, Barretina et al identified YEATS4 as a potential target in WD/DD. ${ }^{39}$ Short hairpin RNA (shRNA)-based knockdown of YEATS4 in LPS cell lines resulted in better antiproliferative effects compared with MDM2. There is accumulating evidence to support a role of YEATS4 in cancer, ${ }^{40}$ such as osteosarcoma, ${ }^{38}$ non-small-cell lung cancer, ${ }^{41}$ etc. Therefore, YEATS 4 may be a suitable target for LPS therapeutic intervention. The 12q13-15 amplicon includes additional genes whose protein products may be potential targets in the future, including DDIT3 (C/EBPzeta), TSPAN31 (SAS), CPM, DYRK2, and others. ${ }^{26}$

\section{Genetically amplified targets outside the I2q 3-I5 amplicon}

In addition to the 12q13-15 amplicon, amplifications of $6 q 23$ or $1 \mathrm{p} 32$, which are never seen in WD, have been detected in DD. ${ }^{42}$ The $6 \mathrm{q} 23$ amplicon includes $A S K 1$, a gene involved in the JNK signaling pathway. ${ }^{43}$ Overexpression of $A S K 1$ 
activates JNK, leading to the activation of some proteins, including JUN, and inactivation of other proteins, particularly peroxisome proliferator-activated receptor gamma (PPAR- $\gamma$ ), which has been demonstrated to play a key role in adipocytic differentiation. ${ }^{44}$ Amplification of 1 p32 including the $C-J U N$ oncogene ${ }^{45}$ is considered to inhibit PPAR- $\gamma$ via $\mathrm{C} / \mathrm{EBP}-\beta$. LPS growth was inhibited by downregulating $C$-JUN via deoxyribozyme (DNAzyme), a drug capable of specific cleavage of target mRNA, ${ }^{46}$ in part by the induction of apoptosis via caspase-10 rather than through the Fas pathway. ${ }^{47}$ Therefore, amplifications of $A S K 1$ and $J U N$ may explain the inhibition of adipocytic differentiation in $\mathrm{DD},{ }^{48}$ and also may be potential therapeutic targets.

$Z I C 1$, one of five ZIC family genes located at chromosome $3 q 24,{ }^{49,50}$ participates in a variety of developmental processes, including neurogenesis and myogenesis. ${ }^{51}$ Recently, ZIC1 has been reported to be involved in the progression of human tumors including endometrial cancers, medulloblastoma, mesenchymal neoplasms, and LPS cancers. ${ }^{49,52}$ Drugs directed against ZIC1 may likewise have therapeutic benefit. $^{53}$

\section{RTKs}

Recent work has shown that WD/DD overexpress RTKs (receptor tyrosine kinases), including MET, AXL, IGFR, and EGFR, all of which may serve as targets of already available small-molecule inhibitors. ${ }^{54}$ Currently, there are several clinical trials with tyrosine kinase inhibitors (TKIs) as a treatment for STS patients. ${ }^{6,55}$ In addition, overexpression of RTKs including RET, IGF1R, and IGF2 ${ }^{56}$ has also been demonstrated in MRC.

\section{Chromosome translocation FUS-DDIT3/EWSR I-DDIT3 fusion protein}

The translocation of $\mathrm{t}(12 ; 16)(\mathrm{q} 13 ; \mathrm{p} 11)$ FUS-DDIT3 fusion (also known as FUS-CHOP) in $\sim 95 \%{ }^{57}$ of cases and the alternative $\mathrm{t}(12 ; 22)(\mathrm{q} 13 ; \mathrm{q} 12)$ EWSR1-DDIT3 fusion (also known as EWSR1-CHOP) present in $<5 \%{ }^{12}$ of cases are to date specific for MRC.

FUS is an RNA-binding protein and is expressed constitutively. The N-terminal part of FUS contains an autonomous transcriptional activation domain required for the oncogenic potential of the FUS-DDIT3 chimeric protein. On the other hand, DDIT3 is a transcription factor belonging to the (c/EBP) family, and has a central role in endoplasmic reticulum (ER) stress and DNA damage response by inducing cell cycle arrest and apoptosis. ${ }^{58}$ The FUS-DDIT3 fusion has distinct functions in comparison to wild-type
DDIT3 and does not induce growth arrest. ${ }^{59}$ Therefore, the FUS-DDIT3 chimeric protein is considered to function as an abnormal transcription factor, and has been shown to induce adipogenic differentiation blockage and cell-cycle control evasion. ${ }^{60}$ Several FUS-DDIT3 target genes that seem to be concerned with MRC development have been identified by use of in vitro and in vivo systems. ${ }^{61-64}$ Downstream targets of FUS-DDIT3 include PPAR- $\gamma 2$ and C/EBP- $\alpha .{ }^{65}$ In addition, FUS-DDIT3 interacts with splicing factors and inhibits alternative splicing. ${ }^{66}$ Göransson et $\mathrm{al}^{67}$ have shown that IL-6 is upregulated in human fibrosarcoma cells transfected with DDIT3-GFP or FUS-DDIT3-GFP and that IL-8 was downregulated after DDIT3 transfection and upregulated after transfection with FUS-DDIT3. In addition, the DDIT3binding $\mathrm{C} / \mathrm{EBP}-\alpha$ has been shown to interact with and inhibit the kinase activity of CDK2 and CDK4. ${ }^{68}$

The Ewing sarcoma breakpoint region (EWSR1), which was initially identified in Ewing sarcoma, a malignant tumor of bone and soft tissue, has also been identified in myxoid LPS, termed EWSR1/DDIT3, with a frequency of $<5 \%$. ${ }^{13,69}$ EWSR1-DDIT3 was also reported to have a lower incidence among the American Indian/Alaskan native and Asian/Pacific Islander populations compared with the white population. ${ }^{70}$ EWSR1-DDIT3 may act as an aberrant transcription factor and affect the phenotypic selection of uncommitted target cells. ${ }^{71,72}$ Suzuki et al $^{73}$ reported that the EWSR1-DDIT3 myxoid LPS fusion protein selectively repressed the transcriptional activity of cell-lineage-specific marker genes in multipotent mesenchymal C3H10T1/2 cells.

\section{Deregulation of signaling pathway $\mathrm{PI} 3 \mathrm{~K} / \mathrm{Akt}$ signaling pathway}

The PI3K/Akt signaling pathway has attracted much scientific attention. ${ }^{74}$ PI3K mutations in the $\mathrm{p} 110 \alpha$ catalytic subunit have been found to be very frequent in MRC tumors and associated with poor prognosis by Barretina et $\mathrm{al}^{39}$ in a study analyzing subtype-specific genomic alterations in 207 STS patients. These findings suggest a potential role for a deregulated Akt pathway in myxoid liposarcomas (MLS)/ round cell LPS (RCL) and support further investigation of PI3K/Akt inhibitors in this histological subtype. Based on the results emerging from other cancer types, PI3K-mutated tumors are highly sensitive to Akt inhibition, ${ }^{75}$ and PI3K sequencing could thus be a potential therapeutic target.

\section{C/EBP- $\alpha$}

$C / E B P-\alpha$ belongs to a family of basic region leucine zipper transcription factors intimately involved in regulating 
terminal differentiation of many cell types. It is expressed at high levels in normal tissues and cell types, but at low levels in cancer cells. ${ }^{76}$ During normal adipogenesis, $C / E B P-\alpha$ and its partner $P P A R-\gamma$ promote each other's expression in a positive feedback loop to maintain high levels of the mRNAs and to maintain the differentiated state. ${ }^{77}$

Recently, it was reported that $C / E B P-\alpha$ and $P P A R-\gamma$ were underexpressed in DD and to a lesser extent in WD. Based on the findings that DD cell lines grown in differentiating conditions lacked the normal induction of $C / E B P-\alpha$ expression despite partially inducing PPAR- $\gamma$ and that PPAR- $\gamma$ levels increased appropriately with the increase in $\mathrm{C} / \mathrm{EBP}-\alpha$ in regular medium (which contains no PPAR- $\gamma$ ligand), Wu et al ${ }^{78}$ suggested that the underexpression of PPAR- $\gamma$ in DD is the consequence, not the cause, of $C / E B P-\alpha$ underexpression, and restoring $C / E B P-\alpha$ may be a useful therapeutic approach for DD.

\section{Peroxisome proliferator-activated receptor gamma}

PPARs are key regulators of normal adipocyte differentiation. $P P A R-\gamma$, one of the isoforms, participates in the terminal adipocyte differentiation pathway. $P P A R-\gamma$ agonist demonstrated antitumor activity in vitro in human LPS cells. ${ }^{79,80}$ Activation of $P P A R-\gamma$ thus represents an attractive target particularly for DD, MRC, and PLS as a mechanism to revert these subtypes to a better differentiated phenotype.

\section{Other potential targets Other genes}

Three genes, TOP2A, PTK7, and CHEK1, were reported to be overexpressed in 140 LPS samples of all subtypes and in LPS cell lines. Once knocked down, these genes in LPS cell lines reduced proliferation and invasiveness and increased apoptosis. ${ }^{81}$ Several point mutations were reported by Barretina et $\mathrm{al}^{39}$ to be identified in CTNNB1 ( $\beta$-catenin), CDH1 (E-cadherin), FBXW7 (a component of the ubiquitin protein ligase complex), and EPHA1 (ephrin A1), each of which has potential oncogenic effects on the LPS cell.

Another therapeutic strategy worthy of further exploration is targeting FUS-DDIT3 downstream effectors. For example, CCL2, CXCL8, IL-6, vascular endothelial growth factor, the proinflammatory protein, and the matrix binder pentraxin 3 have all been found to be specifically downregulated $^{82}$ by FUS-DDIT3 and thus may serve as possible novel therapeutic targets.

\section{Micro-RNA}

Micro-RNAs (miRNAs) are considered to participate in all cellular processes of the organism, ${ }^{83}$ including the development, differentiation, metabolism, and programmed cell death, among others. miRNAs behave as tumor suppressors or oncogenes, depending on whether they target oncogenes or conventional tumor suppressors. The first evidence of miRNA deregulation in chronic lymphocytic leukemias (CLLs) was reported by Calin et al ${ }^{84}$ in 2002. Since then, the number of reports associating miRNA with cancer has been growing exponentially, ${ }^{85}$ from $0.002 \%$ of total cancer reports in 2002 to a current $2 \%$.

Ugras et $\mathrm{al}^{86}$ reported that MiR-143 re-expression selective agents or vectors directed at miR-143 or its targets may have therapeutic value in DD, in a study profiling miRNA expression in 83 samples of WD, DD, and normal adipose tissue. They found highly abundant, downregulated miR-143 in adipose tissue. Restoring miR-143 expression in DD cells induced apoptosis, inhibited proliferation, and decreased expression of polo-like kinase 1 (PLK1). ${ }^{87}$ Therefore, treatment with a PLK1 inhibitor potently induced G2-M growth arrest and apoptosis in LPS cells. MiR- $155^{88}$ was recently found to be highly expressed in WD/DD and to have a significant role in tumorigenesis and progression as an oncogenic miRNA in several cancer models. ${ }^{89-91}$ The role for miR-155 in solid malignancy of mesenchymal origin was first reported by Zhang et al. miR-155 was the most overexpressed miRNA in the growth of DD LPS cell lines. They also identified casein kinase $1 \alpha(\mathrm{CK} 1 \alpha)$ as a direct target of miR-155 control, which enhanced $\beta$-catenin signaling and cyclin D1 expression, as a DD molecular driver. Borjigin et $\mathrm{al}^{92}$ identified plasminogen activator inhibitor-1 (PAI-1), a unique type of serine protease inhibitor and known to be one of the key regulators of tumor invasion and metastasis, as a novel target gene of miR-486, which has been found to be repressed in MRC tissues.

\section{Calreticulin}

A recent study identified several genes that were highly expressed in DD, and an overexpressed gene located in 19p13.1-13.2 chromosome was reported to encode calreticulin (CALR) that can inhibit adipocyte differentiation. Investigating the expression of CALR in 45 cases of LPSs, including 15 DD tumors, at both the protein and mRNA levels, Hisaoka et al reported that CALR was consistently expressed in the DD areas of DD LPS and commonly observed in atypical stromal cells and/or lipoblasts in the WD areas (87\%), whereas large vacuolated adipocytic cells in either the tumors or normal fat were essentially negative. The downregulation of CALR by small-interfering RNA could induce adipogenesis in 
DD cells and reduce cell proliferation..$^{93}$ The authors also reported that the overexpressing gene is a potential target of miR-1275. ${ }^{95}$

\section{Cancer stem cells (CSCs)}

Current knowledge considers tumors as complex heterogeneous organ-like systems with a hierarchical cellular organization. Tumor cells with stem-cell-like properties have been identified in all major human cancers. ${ }^{6} \mathrm{CSCs}$, described as a small population of tumor cells, possess stem-like properties, such as the ability to self-renew and differentiate into more mature cells. ${ }^{94}$ Aldehyde dehydrogenase (ALDH) and the surface molecule $\mathrm{CD} 133$ have recently been shown to be markers of CSCs across multiple tumor types. ${ }^{95}$ In a recent study, Stratford et a ${ }^{96}$ demonstrated that ALDH1 is expressed in 10 out of 10 LPS patient samples. Using an LPS xenograft model, they identified a small population of cells with an inducible stem cell potential, expressing both ALDH and CD133 following culturing in stem cell medium. This potential CSC population, which makes up for $0.1-1.7 \%$ of the cells, displayed increased self-renewing abilities and increased tumorigenicity, giving tumors in vivo from as few as 100 injected cells. All these findings confirmed the existence of CSCs in LPS, and provided targets for novel CSC-specific therapies. Further work, including specifically targeting and killing the CSC population in the model system, is ongoing.

\section{Drugs and trials Drugs for WD/DD MDM2 inhibitors}

The Nutlins, discovered by Vassilev et al at Hoffman-La Roche, ${ }^{99}$ are probably the first potent and specific MDM2 inhibitors. Nutlin-1 and Nutlin-2 are racemic compounds, and Nutlin-3a is an active enantiomer. Nutlin-3a, which has been tested in several preclinical cancer models, demonstrating positive effects, ${ }^{98}$ is a nonpeptide, small-molecule inhibitor of the MDM2-p53 interaction, thus restoring p53 activity. ${ }^{99}$ Studies evaluating the impact of Nutlin-3a on DD cells have demonstrated marked cell cycle arrest and apoptosis in vitro. ${ }^{61}$ MDM2 inhibitors activate p53 in both tumor and normal cells with wild-type $\mathrm{p} 53 ;{ }^{100}$ in other words, an intact p53 pathway is essential. Cells harboring mutated p53 have not been affected by Nutlin-3a. Detailed analysis of aberrations in the p53 pathways may help in predicting tumor sensitivity and resistance to $\mathrm{p} 53$, activating therapy by MDM2 antagonists. ${ }^{101}$ Interestingly, Nutlin-3a has recently been reported to also affect the $\mathrm{Rb}$ pathway by activating
E2F1, and induce apoptosis in null-p53 cancer cells. ${ }^{102}$ Therefore, Nutlin-3 presents an exciting prospect for future targeted therapy. RG7112 (RO5045337) is a member of the Nutlin family and is the first MDM2 antagonist to be assessed clinically (Hoffmann-La Roche) (NCT01164033, NCT01143740, NCT00623870, and NCT00559533). Phase I trials testing RG7112 were reported at the American Society for Clinical Oncology (ASCO) 2011 meeting (RayCoquard et al, Proc. ASCO 2011). ${ }^{104}$ Preliminary clinical data indicate that RG7112 appears to be well tolerated in patients and shows initial evidence of clinical activity and a mechanism of action consistent with targeting of the MDM2-p53 interaction. ${ }^{104,105}$ In a preclinical assessment, the MDM2 antagonist MI-219 (spirooxindole) was reported to trigger an earlier overall biological response (12-24 hours) than Nutlin-3 (48 hours), predominantly in the form of apoptotic cell death. MI-219, but not Nutlin-3, enhanced the auto ubiquitination and degradation of MDM2. Results of the Phase I study of the MDM2 inhibitor JNJ-26854165 (NCT00676910), using continuous daily oral dosing in patients with advanced solid tumors were presented in the 2009 ASCO. ${ }^{106}$ Another MDM2 inhibitor from Hoffm ann-La Roche, RO5503781, whose structure has not been disclosed, entered Phase I clinical trials at the end of 2011 (clinical trials.gov identifier: NCT01462175). A spirooxindole class of MDM2 inhibitors discovered at the University of Michigan in the US has completed IND-enabling studies by Sanofi, and Phase I clinical trials were expected to begin in 2012. Several others MDM2 inhibitors (eg, AT-219; Ascenta) are in late preclinical development. ${ }^{107}$

\section{CDK4 inhibitors}

Recent data ${ }^{108}$ suggest that the future for CDK inhibitors in cancer therapy may be in combinatory strategies. Both preclinical studies and clinical trials have demonstrated that CDK inhibitors can act in synergy with cytotoxic drugs, suggesting that $\mathrm{CDK}$ inhibitors work better when cells are synchronized or arrested in specific cell phases. ${ }^{109}$

Flavopiridol was the first example of a CDK4 inhibitor to be tested in clinical trials. A Phase I trial of doxorubicin and flavopiridol in STS was presented in the 2006 ASCO by D'Adamo et $\mathrm{al}^{110}$ to support that the combination of doxorubicin and flavopiridol is safe, with no unexpected toxicities. Schwartz et al reported the first in-human study of PD 0332991, an oral CDK4/6-specific inhibitor, ${ }^{111}$ enrolling patients who had either non-Hodgkin's lymphoma or Rb-positive advanced solid tumors including WD/DD. They identified the dose-limiting toxicity (DLT) and maximum 
tolerated dose (MTD) of PD 0332991 administered once daily for 21 of 28 days (3/1 schedule) in patients with Rb-positive advanced solid tumors. Recently, the authors screened 48 patients (44 of 48 had CDK4 amplification; 41 of 44 were Rb positive) in a Phase II study of PD 0332991 (NCT01209598) and demonstrated CDK4 inhibitor associated with favorable progression-free survival (PFS) in WD/DD patients with CDK4-amplification and Rb-expression whose disease had progressed despite systemic therapy. ${ }^{112}$ However, they found that no objective treatment responses were seen, suggesting not to support further exploration of flavopiridol as a monotherapy. Co-treatment with PD 0332991 enhances multiple myeloma cell death, and is currently undergoing Phase I and II clinical trials. ${ }^{113,114}$ This kind of synergy of PD 0332991 was also shown with the anti-estrogen tamoxifen and the HER2-targeted therapy trastuzumab in ER-positive breast cancer cell lines. ${ }^{115}$

\section{Drugs for MRC Minor-groove DNA binders}

Trabectedin is a novel chemotherapeutic drug (Ecteinascidin743, ET743) that was isolated from Ecteinascidia turbinata, a tunicate that grows on Caribbean mangrove roots. ${ }^{116}$ It has been approved by European Medicines Agency (EMA) for the second-line therapy of STSs in 2007 and for the secondline therapy of ovarian cancer in 2009. ${ }^{117}$ Trabectedin was shown to be particularly effective in MLS by recent clinical evidence, ${ }^{118-120}$ and the high sensitivity of MLS might be related to the ability of the drug to block the transactivating ability of FUS-DDIT3 fusion protein. ${ }^{121}$ Patients treated with trabectedin could exhibit impressive clinical responses, as was evident in radiological imaging that showed decreased tumor density followed by tumor shrinkage of up to $50 \%$. ${ }^{118}$ In a recent study evaluating the effect of prior chemotherapies on the outcomes of 129 patients with LPS and leiomyosarcoma treated with trabectedin as a 24-hour infusion every 3 weeks, Blay et al ${ }^{122}$ reported that all efficacy outcomes were better compared with patients with more extensive prior therapy. Recently, a multicenter Phase II clinical trial of neoadjuvant trabectedin in patients with localized MRC has been completed at the National Cancer Institute. Gronchi et $\mathrm{al}^{123}$ reported that 3 of 23 assessable patients had pathological complete response (pCR) [13\%; 95\% confidence interval (CI), 3\%-34\%], and that trabectedin $1.5 \mathrm{mg} / \mathrm{m}^{2}$ given as a 24-hour iv infusion every 3 weeks is a therapeutic option in the neoadjuvant setting of MLS.

Similar to trabectidin, brostallicin (PNU-166196) is also a DNA minor-groove binder that alters the transcriptional regulation of FUS-DDIT3-induced genes. ${ }^{124}$ The antitumor activity of brostallicin has been tested in STS patients. Recently, in a Phase II study by the European Organisation for Research and treatment of Cancer (EORTC) of brostallicin in treating patients with locally advanced or metastatic STS, Leahy et al ${ }^{125}$ demonstrated that brostallicin has a manageable toxicity profile and objective tumor responses were infrequent. In addition, they suggested that the drug may warrant further investigation in view of the measured 3-month PFR of $\sim 40 \%$ in a group of patients with a range of other STS histotypes.

\section{Other drugs for LPS}

\section{RTK inhibitors}

Drugs developed to treat diseases caused by activated RTKs are generally divided into two groups: 1) small-molecule inhibitors of the ATP-binding site of the intracellular TKD, ${ }^{126}$ and 2) anti-RTK monoclonal antibodies directing destruction of RTK-expressing cells by the immune system or by interfering with the receptor activation. ${ }^{127}$ RTKs are of established clinical benefit in various cancers, including breast, colorectal, lung, and other tumor types. ${ }^{128}$ For example, imatinib mesylate constitutes the classic example of targeted therapy in mutation-activating c-Kit gastrointestinal stromal tumors (GISTs). ${ }^{129}$ Currently, there are several ongoing clinical trials evaluating different TKIs as treatment for STS patients, ${ }^{55}$ however, seldom are specifically accruing LPS patients.

Pazopanib (GW786034), a synthetic indazolyl pyrimidine, is a novel multitargeted TKI that targets vascular endothelial growth factor receptors (VEGFRs), platelet-derived growth factor receptors (PDGFRs), and c-kit. Pazopanib has demonstrated significant activity mainly in renal cell carcinoma (RCC) and in other malignancies. ${ }^{130,131}$ In 2009, the FDA granted its approval (Votrient ${ }^{\circledR}$, made by GlaxoSmithKline) as a first-line monotherapy or after cytokines-based treatment in patients with advanced RCC. ${ }^{132}$ In a Phase II study enrolling 142 patients with intermediate- or high-grade advanced STS, EORTC (62043) ${ }^{133}$ reported that the PFR (12 weeks) was $18(44 \%)$ of 41 patients in the leiomyosarcoma cohort, $18(49 \%)$ of 37 in synovial sarcomas, $16(39 \%)$ of 41 in other STS types, and only 5 (26\%) of 19 in LPS, which actually was closed after the first stage, and thus, given insufficient activity, they doubted whether any LPS subtypes have any clinical benefit with pazopanib. In a Phase III study carried out by van der Graaf et al in 72 institutions across 13 countries, patients with angiogenesis inhibitor-naive, metastatic, STS progressing despite previous standard chemotherapy were involved. The overall survival was 12.5 months with pazopanib versus 
10.7 months with placebo, which indicates that pazopanib is a new treatment option for patients with metastatic, nonadipocytic, STS after previous chemotherapy. ${ }^{134}$ Another Phase II study specific for advanced LPS patients is currently open (NCT01506596). A Phase II trial evaluating pazopanib activity in advanced and/or metastatic LPS (NCT01692496) after imatinib and sunitinib treatments is undergoing currently. ${ }^{135}$ A Phase III trial of pazopanib in patients with STS whose disease had progressed following or during prior chemotherapy was reported by EORTC (62072) and was presented in $2011 \mathrm{ASCO}$ as an active drug in anthracyclinepretreated metastatic STS patients, with an increase in median PFS of 13 weeks. ${ }^{136}$ In 2012, the FDA and EMA approved pazopanib as second-line chemotherapy for the treatment of patients with advanced nonlipogenic STS, ${ }^{137}$ but still not yet for LPS, so more investigations are needed.

Irradiation when combined with TKIs has demonstrated increased efficacy in preclinical experiments. ${ }^{130,138}$ The first study of sunitinib combined with percutaneous irradiation was published by Kao et al ${ }^{139}$ with $59 \%$ of the patients with oligometastasis of different primary tumors receiving complete or partial remission. Similarly, the combination of radiotherapy with sorafenib might provide clinical benefits in patients with hepatocellular carcinoma (HCC), ${ }^{140}$ metastatic RCC, ${ }^{141}$ as well as gastrointestinal ${ }^{142}$ and other malignancies. Furthermore, the strategy of combining pazopanib with radiotherapy has also been reported recently in cervical cancer (CC) $)^{143}$ and breast cancer, ${ }^{144}$ all of which demonstrate potential benefits to some extent. Although the included entities cannot be compared with STSs, for which irradiation is limited due to the large tumor size and critical anatomic sites such as major vessels and nerves or vital organs, the results of the study provided an application prospect for the combination of radiotherapy and TKIs in LPS. Recently, Porzio et $\mathrm{al}^{145}$ reported that an LPS patient, treated with a total of 23 cycles of sunitinib at $37.5 \mathrm{mg}$ daily in 4-week cycles on a compassionate use basis after receiving radiotherapy and different lines of standard chemotherapy with local progression and lung metastasis, achieved a stable disease in all sites, confirming that sunitinib may be a useful therapeutic tool in the treatment of some cases of pretreated LPS.

\section{Nelfinavir}

LPS cells were shown to express $S R E B P$-1, the underlying mechanism for HIV protease inhibitor (PI) lipodystrophy. ${ }^{146}$ SREBP-1 is a member of the basic helix-loop-helix leucine zipper transcription factor family and promotes lipogenic gene expression, including PPAR- $\gamma$, so SREBP-1 and
PPAR- $\gamma$ cooperatively promote adipogenesis. ${ }^{147,148}$ Nelfinavir (NFV; Vira-cept), one of HIV PIs, has shown promising anticancer activity via multiple pathways. ${ }^{149-151}$ In a recent Phase I trial conducted in 20 patients with unresectable LPS, 17 of whom had WD/DD, 2 MRC, and 1 PLS subtypes, Pan et $\mathrm{al}^{152}$ reported that no dose-limiting toxicities were seen after being treated with NFV, except for 1 patient who had grade-3 pancreatitis. Four patients had stable disease and one with DD experienced a partial response for 14 months. A Phase II trial of NFV in advanced LPS was under way (NCT00233948), and the results have yet to be reported.

\section{PPAR- $\gamma$ agonists}

The PPAR- $\gamma$ agonist not only induced adipocyte differentiation but demonstrated antitumor activity in vitro and in vivo. ${ }^{81,82}$ The activation of PPAR- $\gamma$ results in cell-cycle arrest, induction of apoptosis, inhibition of angiogenesis, and cellular redifferentiation. ${ }^{155}$ However, the results of recent studies are inconclusive due to the low number of enrolled patients and lack of specificity for LPS. Tontonoz et al showed that the PPAR- $\gamma$ agonist pioglitazone effectively induced terminal adipocytic differentiation of human LPS cells. ${ }^{79}$ Furthermore, they demonstrated that a combination of pioglitazone and an RXR- $\alpha$-specific ligand, LG268, might have additive effects in inducing adipocytic differentiation. In a pilot clinical study, troglitazone was administered to 3 patients (two with MRC and one with PLS); histologic analysis revealed remarkable differentiation as well as inhibition of proliferation. ${ }^{88}$ However, in a trial involving 9 LPS patients treated with another PPAR- $\gamma$ agonist rosiglitazone, clinical responses were not observed. ${ }^{154}$ Very recently, Pishvaian et al reported that 5 out 31 patients $(16 \%)$ enrolled in an efatutazone (CS-7017) trial with LPS and 1 patient with MRC had a durable partial response for 690 days while on therapy. ${ }^{155}$ Efatutazone is a novel third-generation PPAR- $\gamma$ agonist that has demonstrated potent anticancer effects in preclinical models. To date, it has not been clarified whether other PPAR- $\gamma$ agonists, such as balaglitazone and sulfonyl hydrazone, have therapeutic efficacy for LPSs.

\section{$\mathrm{PI}$ KK/Akt/mTOR inhibitor}

In a recent study evaluating the effects of NVP-BEZ235 in a panel of rhabdomyosarcoma, osteosarcoma, and Ewing's sarcoma cell lines (LPS was not included), Manara et $\mathrm{al}^{156}$ reported that NVP-BEZ235 effectively blocked the pathway and also showed promising efficacy with either doxorubicin and vincristine. The drug is currently undergoing Phase I/II clinical trials in advanced 
cancer patients. In a mouse xenograft model of DD LPS, Smith et al reported that another PI3K/Akt/mTOR inhibitor, rapamycin, had antiproliferative effects and induced terminal differentiation. ${ }^{157}$

\section{Sorafenib}

Sorafenib is a multitargeted TKI of raf, VEGFR1-3, PDGFRB, c-kit, and flt-3, some of which may be of relevance in STSs. ${ }^{130,131}$ Sunitinib malate has been shown to be safe and effective both in patients with metastatic RCC or imatinibresistant GIST, with FDA approval for both indications. ${ }^{55,135}$ Several trials of these two drugs have been carried out, which were found effective to some degree on LPS patients, but larger samples and LPS-oriented trials are needed.

\section{Eribulin mesylate}

Recently, eribulin mesylate was also reported to have selective activity in LPS. ${ }^{158}$ Eribulin is a nontaxane inhibitor of microtubule dynamics and is currently in Phase III evaluation in LPS and leiomyosarcoma. In an open-label Phase II trial, 128 patients with progressive high-grade STS were divided into four strata: LPS ( $n=37)$, leiomyosarcoma $(n=40)$, synovial sarcoma $(n=19)$, and other STSs $(n=32)$. Finally, $46.9 \%$ of LPS patients were progression-free at 12 weeks.

\section{Conclusion}

LPS is the second common type of STS, which is a diverse family of more than 50 distinct malignancies constituting $\sim 1 \%$ of solid cancers. ${ }^{159}$ Due to its low prevalence and diversity of each subtype's molecular features, there are tremendous difficulties in the development of novel targeted therapies for LPS. Both preclinical and clinical trials converge on the malignancies of greater prevalence, such as gastric cancer, colon cancer, etc, but trials for LPS are really few. Another difficulty lies in the lack of complete samples of each subtype or adequate sample size in one particular research site. In addition, some molecular mechanisms still remain unknown; for example, there is almost no effective targeted therapy for PLS.

To solve these problems, first, the collaboration of different research centers will be needed to deal with both the lack of complete samples of each subtype and lack of adequate sample size, as well as for future larger scale trials. In addition, utilization of the great wealth of data that have been placed in public repositories will help overcome this problem; for example, meta-analysis based on the trials of LPSs are feasible.
Second, according to the characteristics of the development over the recent years, a better understanding of the genetic and molecular aberrations for each histologic subtype will definitely foster the development of novel therapies; thus more basic research on the molecular mechanisms are desperately needed.

Third, because of some common mechanisms in human cells, drugs that have efficacy to treat a certain disease may also be effective in the treatment of some others. For example, the PPAR- $\gamma$ agonist thiazolidinedione was first used as an antidiabetic drug and later on was also reported to be effective for LPS. ${ }^{90}$ Similarly, some other mechanisms such as C/EBP- $\alpha$, CSCs, and miRNA may provide novel research approaches.

Furthermore, as mentioned above, combination approaches, such as those of radiotherapy and TKIs and of CDK inhibitors and cytotoxic drugs, may be an attractive potential therapy.

In conclusion, in the past years, a better understanding of molecular mechanisms of distinct LPS subtypes has led to the development of targeted therapy. However, we are still in the early stages of translating these findings into clinical application. More research work is needed.

\section{Acknowledgment}

The authors wish to thank Prof Qinyuan Lou for critically reading the manuscript.

\section{Disclosure}

The authors report no conflicts of interest in this work.

\section{References}

1. Dodd LG. Update on liposarcoma: a review for cytopathologists. Diagn Cytopathol. 2012;40:1122-1131

2. Matushansky I, Hernando E, Socci ND, et al. A developmental model of sarcomagenesis defines a differentiation-based classification for liposarcomas. Am J Pathol. 2008;172:1069-1080.

3. Fletcher CDM, Bridge JA, Hogendoorn PCW, Mertens F, editors. World Health Organization Classification of Tumours of Soft Tissue and Bone. 4th ed. Lyon: IARC Press; 2013.

4. Fletcher CDM, Unni KK, Mertens F, editors. World Health Organization Classification of Tumours. Pathology and Genetics of Tumours of Soft Tissue and Bone. Lyon: IARC Press; 2002:35-44.

5. Steen S, Stephenson G. Current treatment of soft tissue sarcoma. Proc (Bayl Univ Med Cent). 2008;21:392-396.

6. Sleijfer S, Ouali M, van Glabbeke M, et al. Prognostic and predictive factors for outcome to first-line ifosfamide-containing chemotherapy for adult patients with advanced soft tissue sarcomas: an exploratory, retrospective analysis on large series from the European Organization for Research and Treatment of Cancer - Soft Tissue and Bone Sarcoma Group (EORTC-STBSG). Eur J Cancer. 2010;46:72-83.

7. Johnson KA, Brown PH. Drug development for cancer chemoprevention: focus on molecular targets. Semin Oncol. 2010;37:345-358. 
8. Singer S, Antonescu CR, Riedel E, Brennan MF. Histologic subtype and margin of resection predict pattern of recurrence and survival for retroperitoneal liposarcoma. Ann Surg. 2003;238:358-370.

9. Zagars GK, Ballo MT, Pisters PW, Pollock RE, Patel SR, Benjamin RS. Surgical margins and reresection in the management of patients with soft tissue sarcoma using conservative surgery and radiation therapy. Cancer. 2003;97:2544-2553.

10. Kalluri K, Weinberg RA. The basics of epithelia-mesenchymal transition. J Clin Invest. 2009;119:1420-1428.

11. Wang Z, Li Y, Ahmad A, et al. Targeting miRNAs involved in cancer stem cells and EMT regulation: an emerging concept in overcoming drug resistance. Drug Resist Updat. 2010;13:109-118.

12. Antonescu CR, Tschernyavsky SJ, Decuseara R, et al. Prognostic impact of P53 status TLS-CHOP fusion transcript structure, and histological grade in myxoid liposarcoma: a molecular and clinicopathologic study of 82 cases. Clin Cancer Res. 2001;7:3977-3987.

13. Fiore M, Grosso F, Lo Vullo S, et al. Myxoid/round cell and pleomorphic liposarcomas: prognostic factors and survival in a series of patients treated at a single institution. Cancer. 2007;109:2522-2531.

14. Patel SR, Burgess MA, Plager C, Papadopoulos NE, Linke KA, Benjamin RS. Myxoid liposarcoma. Experience with chemotherapy. Cancer. 1994;74:1265-1269.

15. Guadagnolo BA, Zagars GK, Ballo MT, et al. Excellent local control rates and distinctive patterns of failure inmyxoid liposarcoma treated with conservation surgery and radiotherapy. Int $J$ Radiat Oncol Biol Phys. 2008;70:760-765.

16. Jones RL, Fisher C, Al-Muderis O, Judson IR. Differential sensitivity of liposarcoma subtypes to chemotherapy. Eur J Cancer 2005;41:2853-2860.

17. Nishio J. Contributions of cytogenetics and molecular cytogenetics to the diagnosis of adipocytic tumors. J Biomed Biotechnol. 2011;2011:524067.

18. Conyers R, Young S, Thomas DM. Liposarcoma: molecular genetics and therapeutics. Sarcoma. 2011;2011:483154.

19. Nishio J, Iwasaki H, Nabeshima K, Naito M. Cytogenetics and molecular genetics of myxoid soft-tissue sarcomas. Genet Res Int 2011;2011:497148.

20. Suzuki K, Matsui Y, Endo K, et al. Myxoid liposarcoma with EWSCHOP type 1 fusion gene. Anticancer Res. 2010;30:4679-4683.

21. Hornick JL, Bosenberg MW, Mentzel T, McMenamin ME, Oliveira AM, Fletcher CD. Pleomorphic liposarcoma: clinicopathologic analysis of 57 cases. Am J Surg Pathol. 2004;28:1257-1267.

22. Ghadimi MP, Liu P, Peng T, et al. Pleomorphic liposarcoma: clinical observations and molecular variables. Cancer. 2011;117: 5359-5369.

23. Pedeutour F, Forus A, Coindre JM, et al. Structure of the supernumerary ring and giant rod chromosomes in adipose tissue tumors. Genes Chromosomes Cancer. 1999;24:30-41.

24. Mertens F, Fletcher CD, Dal Cin P, et al. Cytogenetic analysis of 46 pleomorphic soft tissue sarcomas and correlation with morphologic and clinical features: a report of the CHAMP Study Group. Chromosomes and MorPhology. Genes Chromosomes Cancer. 1998; 22:16e25.

25. Rosai J, Akerman M, Dal Cin P, et al. Combined morphologic and karyotypic study of 59 atypical lipomatous tumors. Evaluation of their relationship and differential diagnosis with other adipose tissue tumors (a report of the CHAMP Study Group). Am J Surg Pathol. 1996;20:1182e9.

26. Italiano A, Bianchini L, Keslair F, et al. HMGA2 is the partner of MDM2 in well-differentiated and dedifferentiated liposarcomas whereas CDK4 belongs to a distinct inconsistent amplicon. Int $J$ Cancer. 2008;122:2233-2241.

27. Weaver J, Downs-Kelly E, Goldblum JR, et al. Fluorescence in situ hybridization for MDM2 gene amplification as a diagnostic tool in lipomatous neoplasms. Mod Pathol. 2008;21:943-949.

28. Aleixo PB, Hartmann AA, Menezes IC, Meurer RT, Oliveira AM. Can MDM2 and CDK4 make the diagnosis of well differentiated/ dedifferentiated liposarcoma? An immunohistochemical study on 129 soft tissue tumours. J Clin Pathol. 2009;62:1127-1135.
29. Momand J, Wu HH, Dasgupta G. MDM2-master regulator of the p53 tumor suppressor protein. Gene. 2000;242:15-29.

30. Teodoro JG, Evans SK, Green MR. Inhibition of tumor angiogenesis by p53: a new role for the guardian of the genome. $J$ Mol Med. 2007;85:1175-1186.

31. Freedman DA, Wu L, Levine AJ. Functions of the MDM2 oncoprotein. Cell Mol Life Sci. 1999;55:96-107.

32. Juven-Gershon T, Oren M. Mdm2: the ups and downs. Mol Med. 1999;5:71-83.

33. Loughran $\mathrm{O}$, La Thangue NB. Apoptotic and growthpromoting activity of E2F modulated by MDM2. Mol Cell Biol. 2000;20:2186-2197.

34. Ortega S, Malumbres M, Barbacid M. Cyclin D-dependent kinases, INK4 inhibitors and cancer. Biochim Biophys Acta. 2002;1602:73-87.

35. Weinberg RA. The retinoblastoma protein and cell cycle control. Cell. 1995;81:323-330.

36. Bellacchio E, Paggi MG. Understanding the targeting of the RB family proteins by viral oncoproteins to defeat their oncogenic machinery. J Cell Physiol. 2013;228:285-291.

37. Llanos S, Efeyan A, Monsech J, Dominguez O, Serrano M. Highthroughput loss-of-function screening identifies novel p53 regulators. Cell Cycle. 2006;5:1880-1885.

38. Park JH, Roeder RG. GAS41 is required for repression of the $\mathrm{p} 53$ tumor suppressor pathway during normal cellular proliferation. Mol Cell Biol. 2006;26:4006-4016.

39. Barretina J, Taylor BS, Banerji S, et al. Subtype-specific genomic alterations define new targets for soft-tissue sarcoma therapy. Nat Genet. 2010;42:715-721

40. Santarius T, Shipley J, Brewer D, Stratton MR, Cooper CS. A census of amplified and overexpressed human cancer genes. Nat Rev Cancer. 2010;10:59-64.

41. Pikor LA, Lockwood WW, Thu KL, et al. YEATS4 is a novel oncogene amplified in non-small cell lung cancer that regulates the $\mathrm{p} 53$ pathway. Cancer Res. 2013;73(24):7301-7312.

42. Chibon F, Mariani O, Derré J, et al. A subgroup of malignant fibrous histiocytomas in associated with genetic changes similar to those of well-differentiated liposarcomas. Cancer Genet Cytogenet. 2002;139: 24-29.

43. Chibon F, Mariani O, Derre J, et al. ASK1 (MAP3K5) as a potential therapeutic target in malignant fibrous histiocytomas with 12q14-q15 and 6q23 amplifications. Genes Chromosomes Cancer. 2004;40:32-37.

44. Castriota G, Thompson GM, Lin Y, Scherer PE, Moller DE, Berger JP. Peroxisome proliferator-activated receptor gamma agonists inhibit adipocyte expression of alpha1-acid glycoprotein. Cell Biol Int. 2007;31:586-591.

45. Mariani O, Brennetot C, Coindre JM, et al. JUN oncogene amplification and overexpression block adipocytic differentiation in highly aggressive sarcomas. Cancer Cell. 2007;11:361-374.

46. Santoro SW, Joyce GF. A general purpose RNA-cleaving DNA enzyme. Proc Natl Acad Sci U S A. 1997;94:4262-4266.

47. Dass CR, Galloway SJ, Clark JC, Khachigian LM, Choong PF. Involvement of c-jun in human liposarcoma growth: supporting data from clinical immunohistochemistry and DNAzyme efficacy. Cancer Biol Ther. 2008;7:1297-1301.

48. Coindre JM, Pédeutour F, Aurias A. Well-differentiated and dedifferentiated liposarcomas. Virchows Arch. 2010;456:167-179.

49.Aruga J, Yokota N, Hashimoto M, Furuichi T, Fukuda M, Mikoshiba K. A novel zinc finger protein, Zic, is involved in neurogenesis, especially in the cell lineage of cerebellar granule cells. $J$ Neurochem. 1994;63: $1880-1890$.

50. Maurus D, Harris WA. Zic-associated holoprosencephaly: zebrafish ZIC1 controls midline formation and forebrain patterning by regulating Nodal, Hedgehog, and retinoic acid signaling. Genes Dev. 2009;23:1461-1473.

51. Pourebrahim R, Van Dam K, Bauters M, et al. ZIC1 gene expression is controlled by DNA and histone methylation in mesenchymal proliferations. FEBS Lett. 2007;581(26):5122-5126.

52. Merzdorf CS. Emerging roles for zic genes in early development. Dev Dyn. 2007;236(4):922-940. 
53. Brill E, Gobble R, Angeles C, et al. ZIC1 overexpression is oncogenic in liposarcoma. Cancer Res. 2010;70(17):6891-6901.

54. Peng T, Zhang P, Liu J, et al. An experimental model for the study of well differentiated and dedifferentiated liposarcoma; deregulation of targetable tyrosine kinase receptors. Lab Invest. 2011;91(3):392-403.

55. Demetri GD, van Oosterom AT, Garrett CR, et al. Efficacy and safety of sunitinib in patients with advanced gastrointestinal stromal tumour after failure of imatinib: a randomised controlled trial. Lancet. 2006;368:1329-1338.

56. Lanckohr C, Kasprzynski A, Klein-Hitpass L, et al. Identification of genes over-expressed in myxoid/round cell liposarcoma DNA microarray analysis and immunohistochemical correlation. Pathologe. 2010;31:60-66.

57. Antonescu CR, Elahi A, Humphrey M, et al. Specificity of TLS-CHOP rearrangement for classic myxoid/round cell liposarcoma: absence in predominantly myxoid well-differentiated liposarcomas. J Mol Diagn. 2000;2:132-138.

58. Katarina E, Helena W, Christina K, et al. The myxoid/round cell liposarcoma fusion oncogene FUS-DDIT3 and the normal DDIT3 induce a liposarcoma phenotype in transfected human fibrosarcoma cells. $\mathrm{Am}$ J Pathol. 2006;168(5):1642-1653.

59. Barone MV, Crozat A, Tabaee A, Philipson L, Ron D. CHOP(GADD153) and its oncogenic variant, TLS-CHOP, have opposing effects on the induction of G1/S arrest. Genes Dev. 1994;8(4):453-464.

60. Adelmant G, Gilbert JD, Freytag SO. Human translocation liposarcomaCCAAT/enhancer binding protein (C/EBP) homologous protein (TLS-CHOP) oncoprotein prevents adipocyte differentiation by directly interfering with C/EBPbeta function. $J$ Biol Chem. 1998;273:15574-15581.

61. Kuroda M, Wang X, Sok J, et al. Induction of a secreted protein by the myxoid liposarcoma oncogene. Proc Natl Acad Sci U S A. 1999;96:5025-5030.

62. Andersson MK, Goransson M, Olofsson A, Andersson C, Aman P. Nuclear expression of FLT1 and its ligand PGF in FUS-DDIT3 carrying myxoid liposarcomas suggests the existence of an intracrine signaling loop. BMC Cancer. 2010;10:249.

63. Perez-Mancera PA, Bermejo-Rodriguez C, Sanchez-Martin M, AbolloJimenez F, Pintado B, Sanchez-Garcia I. FUS-DDIT3 prevents the development of adipocytic precursors in liposarcoma by repressing PPARgamma and C/EBPalpha and activating eIF4E. PLoS One. 2008;3:e2569.

64. Göransson M, Elias E, Ståhlberg A, et al. Myxoid liposarcoma FUSDDIT3 fusion oncogene induces C/EBP beta-mediated interleukin 6 expression. Int J Cancer. 2005;115(4):556-560.

65. Oikawa K, Tanaka M, Itoh S, et al. A novel oncogenic pathway by TLSCHOP involving repression of MDA-7/IL-24 expression. Br J Cancer. 2012;106(12):1976-1979

66. Pérez-Mancera PA, Bermejo-Rodríguez C, Sánchez-Martín M, Abollo-Jiménez F, Pintado B, Sánchez-García I. FUS-DDIT3 prevents the development of adipocytic precursors in liposarcoma by repressing PPARgamma and C/EBPalpha and activating eIF4E. PLoS One. 2008;3: e2569.

67. Rapp TB, Yang L, Conrad EU 3rd, Mandahl N, Chansky HA. RNA splicing mediated by YB-1 is inhibited by TLS/CHOP in human myxoid liposarcoma cells. J Orthop Res. 2002;20(4):723-729.

68. Wang H, Iakova P, Wilde M, et al. C/EBPalpha arrests cell proliferation through direct inhibition of Cdk2 and Cdk4. Mol Cell. $2001 ; 8(4): 817-828$

69. Antonescu CR, Elahi A, Healey JH, et al. Monoclonality of multifocal myxoid liposarcoma: confirmation by analysis of TLS-CHOP or EWSCHOP rearrangements. Clin Cancer Res. 2000;6:2788-2793.

70. Worch J, Cyrus J, Goldsby R, Matthay KK, Neuhaus J, DuBois SG. Racial differences in the incidence of mesenchymal tumors associated with EWSR1 translocation. Cancer Epidemiol Biomarkers Prev. 2011;20(3):449-453.

71. Pérez-Mancera PA, Sánchez-García I. Understanding mesenchymal cancer: the liposarcoma-associated FUS-DDIT3 fusion gene as a model. Semin Cancer Biol. 2005;15:206-214.
72. Rodriguez R, Rubio R, Gutierrez-Aranda I, et al. FUS-CHOP fusion protein expression coupled to $\mathrm{p} 53$ deficiency induces liposarcoma in mouse but not in human adipose-derived mesenchymal stem/stromal cells. Stem Cells. 2011;29:179-192.

73. Suzuki K, Matsui Y, Higashimoto M, et al. Myxoid liposarcomaassociated EWSR1-DDIT3 selectively represses osteoblastic and chondrocytic transcription in multipotent mesenchymal cells. PLoS One. 2012;7(5):e36682.

74. LoPiccolo J, Blumenthal GM, Bernstein WB, Dennis PA. Targeting the PI3K/Akt/mTOR pathway: effective combinations and clinical considerations. Drug Resist Updat. 2008;11:32-50.

75. Huang $\mathrm{CH}$, Mandelker D, Schmidt-Kittler O, et al. The structure of a human $\mathrm{p} 110 \mathrm{alpha/p} 85 \mathrm{alph}$ complex elucidates the effects of oncogenic PI3Kalpha mutations. Science. 2007;318:1744-1748.

76. Bennett KL, Hackanson B, Smith LT, et al. Tumor suppressor activity of CCAAT/enhancer binding protein alpha is epigenetically downregulated in head and neck squamous cell carcinoma. Cancer Res. 2007;67:4657-4664.

77. Saladin R, Fajas L, Dana S, Halvorsen YD, Auwerx J, Briggs M. Differential regulation of peroxisome proliferator activated receptor gamma1 (PPARgamma1) and PPARgamma2 messenger RNA expression in the early stages of adipogenesis. Cell Growth Differ. 1999;10:43-48.

78. Wu YV, Okada T, DeCarolis P, et al. Restoration of C/EBP $\alpha$ in dedifferentiated liposarcoma induces G2/M cell cycle arrest and apoptosis. Genes Chromosomes Cancer. 2012;51(4):313-327.

79. Tontonoz P, Singer S, Forman BM, et al. Terminal differentiation of human liposarcoma cells induced by ligands for peroxisome proliferator-activated receptor gamma and the retinoid X receptor. Proc Natl Acad Sci U S A. 1997;94:237-241.

80. Demetri GD, Fletcher CD, Mueller E, et al. Induction of solid tumor differentiation by the peroxisome proliferator-activated receptor-gamma ligand troglitazone in patients with liposarcoma. Proc Natl Acad Sci US A. 1999;96:3951-3956.

81. Gobble RM, Qin LX, Brill ER, et al. Expression profiling of liposarcoma yields a multigene predictor of patient outcome and identifies genes that contribute to liposarcomagenesis. Cancer Res. 2011; 71(7):2697-2705.

82. Germano G, Frapolli R, Simone M, et al. Antitumor and anti-inflammatory effects of trabectedin on human myxoid liposarcoma cells. Cancer Res. 2010;70:2235-2244.

83. Kim VN, Nam JW. Genomics of microRNA. Trends Genet. 2006;3(22): 165-173.

84. Calin GA, Dumitru CD, Shimizu M, et al. Frequent deletions and down-regulation of micro-RNA genes miR15 and miR16 at 13q14 in chronic lymphocytic leukemia. Proc Natl Acad Sci U S A. 2002;24(99):15524-15529.

85. Soriano A, Jubierre L, Almazán-Moga A, et al. microRNAs as pharmacological targets in cancer. Pharmacol Res. 2013;75:3-14.

86. Ugras S, Brill E, Jacobsen A, et al. Small RNA sequencing and functional characterization reveals microRNA-143 tumor suppressor activity in liposarcoma. Cancer Res. 2011;71(17):5659-5669.

87. Singer S, Socci ND, Ambrosini G, et al. Gene expression profiling of liposarcoma identifies distinct biological types/subtypes and potential therapeutic targets in well-differentiated and dedifferentiated liposarcoma. Cancer Res. 2007;67:6626-6636.

88. Zhang P, Bill K, Liu J, et al. MiR-155 Is a liposarcoma oncogene that targets casein kinase- $1 \alpha$ and enhances $\beta$-catenin signaling. Cancer Res. 2012;72(7):1751-1762.

89. Kong W, He L, Coppola M, et al. MicroRNA-155 regulates cell survival, growth and chemosensitivity by targeting FOXO3a in breast cancer. $J$ Biol Chem. 2010;285:17869-17879.

90. Jiang S, Zhang H-W, Lu M-H, et al. MicroRNA-155 functions as an OncomiR in breast cancer by targeting the suppressor of cytokine signaling 1 gene. Cancer Res. 2010;70:3119-3127.

91. Xiang X, Zhuang X, Ju S, et al. miR-155 promotes macroscopic tumor formation yet inhibits tumor dissemination from mammary fat pads to the lung by preventing EMT. Oncogene. 2011;30: 3340-3353. 
92. Borjigin N, Ohno $\mathrm{S}, \mathrm{Wu} \mathrm{W}$, et al. TLS-CHOP represses miR-486 expression, inducing upregulation of a metastasis regulator PAI-1 in human myxoid liposarcoma. Biochem Biophys Res Commun. 2012;427(2):355-360.

93. Hisaoka M, Matsuyama A, Nakamoto M. Aberrant calreticulin expression is involved in the dedifferentiation of dedifferentiated liposarcoma. Am J Pathol. 2012;180(5):2076-2083.

94. Van Glabbeke M, van Oosterom AT, Oosterhuis JW, et al. Prognostic factors for the outcome of chemotherapy in advanced soft tissue sarcoma: an analysis of 2,185 patients treated with anthracyclinecontaining first-line regimens - a European organization for research and treatment of cancer soft tissue and bone sarcoma group study. J Clin Oncol. 1999;17:150-157.

95. Yin AH, Miraglia S, Zanjani ED, et al. AC133, a novel marker for human hematopoietic stem and progenitor cells. Blood. 1997;90: 5002-5012.

96. Stratford EW, Castro R, Wennerstrom A, et al. Liposarcoma cells with aldefluor and CD133 activity have a cancer stem cell potential Clin Sarcoma Res. 2011;1(1):1-11

97. Xie H, Ng D, Savinov SN, et al. Structure-activity relationships in the binding of chemically derivatized CD4 to gp120 from human immunodeficiency virus. J Med Chem. 2007;50:4898-4908.

98. Maerken TV, Speleman F, Vermeulen J, et al. Small-molecule MDM2 antagonists as a new therapy concept for neuroblastoma. Cancer Res. 2006;66:9646-9655.

99. Vassilev LT, Vu BT, Graves B, et al. In vivo activation of the p53 pathway by small-molecule antagonists of MDM2. Science. 2004;303:844-848.

100. Bernstein PR, Buschauer A, Georg GI, et al. Topics in Medicinal Chemistry. Heidelberg, New York, Dordrecht, London: Springer; 2012.

101. Ohnstad HO, Castro R, Sun J, et al. Correlation of TP53 and MDM2 genotypes with response to therapy in sarcoma. Cancer. 2013;119(5):1013-1022.

102. Polager S, Ginsberg D. p53 and E2f: partners in life and death. Nat Rev Cancer. 2009;9:738-748.

103. Cassier PA, Labidi-Galy SI, Heudel P, et al. Therapeutic pipeline for soft-tissue sarcoma. Expert Opin Pharmacother. 2011;12(16): 2479-2491.

104. Ray-Coquard I, Blay JY, Italiano A, et al. Effect of the MDM2 antagonist RG7112 on the P53 pathway in patients with MDM2-amplified, well-differentiated or dedifferentiated liposarcoma: an exploratory proof-of-mechanism study. Lancet Oncol. 2012;13(11): $1133-1140$

105. Constantinidou A, Pollack SM, Jones RL. MDM2 inhibition in liposarcoma: a step in the right direction. Lancet Oncol. 2012;13(11): 1070-1071.

106. Yuan Y, Liao YM, Hsueh CT, Mirshahidi HR. Novel targeted therapeutics: inhibitors of MDM2, ALK and PARP. J Hematol Oncol. 2011;4(1):16.

107. Cheok CF, Verma CS, Baselga J, Lane DP. Translating p53 into the clinic. Nat Rev Clin Oncol. 2011;8(1):25-37.

108. Stone A, Sutherland RL, Musgrove EA. Inhibitors of cell cycle kinases: recent advances and future prospects as cancer therapeutics. Crit Rev Oncog. 2012;17:175-198.

109. Rizzolio F, Tuccinardi T, Caligiuri I, Lucchetti C, Giordano A. CDK inhibitors: from the bench to clinical trials. Curr Drug Targets. 2010;11:279-290.

110. D'Adamo DR, Scheu K, Anderson SE, et al. A phase I trial of doxorubicin and flavopiridol in soft tissue sarcoma. J Clin Oncol. 2006;24(18S, June 20 suppl):9523. [ASCO Annual Meeting Proceedings (Post-Meeting Edition)].

111. Schwartz GK, LoRusso PM, Dickson MA, et al. Phase I study of PD 0332991, a cyclin-dependent kinase inhibitor, administered in 3-week cycles (Schedule 2/1). Br J Cancer. 2011;104: $1862-1868$.

112. Morris DG, Bramwell VH, Turcotte R, et al. A phase II study of flavopiridol in patients with previously untreated advanced soft tissue sarcoma. Sarcoma. 2006;64374:1-7.
113. Menu E, Garcia J, Huang X, et al. A novel therapeutic combination using PD 0332991 and bortezomib: study in the 5T33MM myeloma model. Cancer Res. 2008;68:5519-5523.

114. Baughn LB, Di Liberto M, Wu K, et al. A novel orally active small molecule potently induces G1 arrest in primary myeloma cells and prevents tumor growth by specific inhibition of cyclin-dependent kinase 4/6. Cancer Res. 2006;66:7661-7667.

115. Finn RS, Dering J, Conklin D, et al. PD 0332991, a selective cyclin D kinase $4 / 6$ inhibitor, preferentially inhibits proliferation of luminal estrogen receptor-positive human breast cancer cell lines in vitro. Breast Cancer Res. 2009;11:R77.

116. Erba E, Bergamaschi D, Bassano L, et al. Ecteinascidin-743 (ET-743), a natural marine compound, with a unique mechanism of action. Eur J Cancer. 2001;37:97-105.

117. Di Giandomenico S, Frapolli R, Bello E, et al. Mode of action of trabectedin in myxoid liposarcomas. Oncogene. 2013;33(44):5201-5210.

118. Grosso F, Jones RL, Demetri GD, et al. Efficacy of trabectedin (ecteinascidin-743) in advanced pretreated myxoid liposarcomas: a retrospective study. Lancet Oncol. 2007;8:595-602.

119. Grosso F, Sanfilippo R, Virdis E, et al. Trabectedin in myxoid liposarcomas (MLS): a long-term analysis of a single-institution series. Ann Oncol. 2009;20:1439-1444.

120. Charytonowicz E, Terry M, Coakley K, et al. PPARgamma agonists enhance ET-743-induced adipogenic differentiation in a transgenic mouse model of myxoid round cell liposarcoma. J Clin Invest. 2012;122:886-898.

121. Forni C, Minuzzo M, Virdis E, et al. Trabectedin (ET-743) promotes differentiation in myxoid liposarcoma tumors. Mol Cancer Ther. 2009;8:449-457.

122. Blay JY, Casali P, Nieto A, Tanović A, Le Cesne A. Efficacy and safety of trabectedin as an early treatment for advanced or metastatic liposarcoma and leiomyosarcoma. Future Oncol. 2014;10(1):59-68.

123. Gronchi A, Bui BN, Bonvalot S, et al. Phase II clinical trial of neoadjuvant trabectedin in patients with advanced localized myxoid liposarcoma. Ann Oncol. 2012;23(3):771-776.

124. Broggini M, Marchini S, Fontana E, Moneta D, Fowst C, Geroni C. Brostallicin: a new concept in minor groove DNA binder development. Anticancer Drugs. 2004;15:1-6.

125. Leahy M, Ray-Coquard I, Verweij J, et al. Brostallicin, an agent with potential activity in metastatic soft tissue sarcoma: a phase II study from the European Organisation for Research and Treatment of Cancer Soft Tissue and Bone Sarcoma Group. Eur J Cancer. 2007;43:308-315.

126. Shawver LK, Slamon D, Ullrich A. Smart drugs: tyrosine kinase inhibitors in cancer therapy. Cancer Cell. 2002;1:117-123.

127. Reichert JM, Valge-Archer VE. Development trends for monoclonal antibody cancer therapeutics. Nat Rev Drug Discov. 2007;6:349-356.

128. Johnson BE, Jänne PA. Rationale for a phase II trial of pertuzumab, a HER-2 dimerization inhibitor, in patients with non-small cell lung cancer. Clin Cancer Res. 2006;12:4436s-4440s.

129. Hirota S, Isozaki K, Moriyama Y, et al. Gain-of-function mutations of c-kit in human gastrointestinal stromal tumors. Science. 1998;279:577-580.

130. Sternberg CN, Davis ID, Mardiak J, et al. Pazopanib in locally advanced or metastatic renal cell carcinoma: results of a randomized phase III trial. J Clin Oncol. 2010;28:1061-1068.

131. Hutson TE, Davis ID, Machiels JP, et al. Efficacy and safety of pazopanib in patients with metastatic renal cell carcinoma. $J$ Clin Oncol. 2010;28:475-480.

132. National Cancer Institute. FDA Approval for Pazopanib Hydrochloride; 2013. Available from: http://www.cancer.gov/cancertopics/ druginfo/fda-pazopanibhydrochloride. Accessed May 10, 2012.

133. Sleijfer S, Ray-Coquard I, Papai Z, et al. Pazopanib, a multikinase angiogenesis inhibitor, in patients with relapsed or refractory advanced soft tissue sarcoma: a phase II study from the European Organisation for Research and Treatment of Cancer-Soft Tissue and Bone Sarcoma Group (EORTC study 62043). J Clin Oncol. 2009;27(19):3126-3132. 
134. van der Graaf WT, Blay JY, Chawla SP, et al; EORTC Soft Tissue and Bone Sarcoma Group, PALETTE Study Group. Pazopanib for metastatic soft-tissue sarcoma (PALETTE): a randomised, double-blind, placebocontrolled phase 3 trial. Lancet. 2012;379(9829):1879-1886.

135. Ranieri G, Mammi M, Donato Di Paola E, et al. Pazopanib a tyrosine kinase inhibitor with strong anti-angiogenetic activity: a new treatment for metastatic soft tissue sarcoma. Crit Rev Oncol Hematol. 2014;89(2):322-329.

136. Van Der Graaf WT, Blay J, Chawla SP, et al. PALETTE: a randomized, double-blind, phase III trial of pazopanib versus placebo in patients (pts) with soft-tissue sarcoma (STS) whose disease has progressed during or following prior chemotherapy - an EORTC STBSG Global Network Study (EORTC 62072). J Clin Oncol. 2011;29(15 suppl).

137. Ranieri G, Mammì M, Donato Di Paola E, et al. Pazopanib a tyrosine kinase inhibitor with strong anti-angiogenetic activity: a new treatment for metastatic soft tissue sarcoma. Crit Rev Oncol Hematol. 2014;89(2):322-329.

138. Nieder C, Wiedenmann N, Andratschke N, Molls M. Current status of angiogenesis inhibitors combined with radiation therapy. Cancer Treat Rev. 2006;32:348-364.

139. Kao J, Packer S, Vu HL. Phase 1 study of concurrent sunitinib and image-guided radiotherapy followed by maintenance sunitinib for patients with oligometastases: acute toxicity and preliminary response. Cancer. 2009; 115:3571-3580.

140. Hsieh CH, Jeng KS, Lin CC, et al. Combination of sorafenib and intensity modulated radiotherapy for unresectable hepatocellular carcinoma. Clin Drug Investig. 2009;29(1):65-71.

141. Kasibhatla M, Steinberg P, Meyer J, Ernstoff MS, George DJ. Radiation therapy and sorafenib: clinical data and rationale for the combination in metastatic renal cell carcinoma. Clin Genitourin Cancer. 2007;5(4):291-294.

142. Plastaras JP, Kim SH, Liu YY, et al. Cell cycle-dependent and schedule-dependent antitumor effects of sorafenib combined with radiation. Cancer Res. 2007;67(19):9443-9454.

143. Monk B, Mas L, Zarba JJ, et al. A randomized phase II study: pazopanib (P) versus lapatinib (L) versus combination of pazopanib/ lapatinib $(\mathrm{L}+\mathrm{P})$ in advanced and recurrent cervical cancer $(\mathrm{CC})$. J Clin Oncol. 2009;27(15S, May 20 suppl):5520. [Meeting Abstracts].

144. Goyal S, Shah S, Khan AJ, Danish H, Haffty BG. Evaluation of acute locoregional toxicity in patients with breast cancer treated with adjuvant radiotherapy in combination with pazopanib. ISRN Oncol. 2012;2012:5, Article ID 896202.

145. Porzio R, Bella MA, Rossi G, Ardizzoni A. Long-lasting clinical benefit of sunitinib malate in the treatment of a case of heavily pre-treated metastatic liposarcoma. Anticancer Res. 2013;33(3):1061-1063.

146. Chow WA, Guo S, Valdes-Albini F. Nelfinavir induces liposarcoma apoptosis and cell cycle arrest by upregulating sterol regulatory element binding protein-1. Anticancer Drugs. 2006;17:891-903.
147. Kim JB, Spiegelman BM. ADD1/SREBP1 promotes adipocyte differentiation and gene expression linked to fatty acid metabolism. Genes Dev. 1996;1(0):1096-1107.

148. Horton JD, Goldstein JL, Brown MS. SREBPs: activators of the complete program of cholesterol and fatty acid synthesis in the liver. J Clin Invest. 2002;109:1125-1131.

149. Brunner TB, Geiger M, Grabenbauer GG, et al. Phase I trial of the human immunodeficiency virus protease inhibitor nelfinavir and chemoradiation for locally advanced pancreatic cancer. J Clin Oncol. 2008;26:2699-2706

150. Pore N, Gupta AK, Cerniglia GJ, Maity A. HIV protease inhibitors decrease VEGF/HIF-1alpha expression and angiogenesis in glioblastoma cells. Neoplasia. 2006;8:889-895.

151. Ikezoe T, Saito T, Bandobashi K, Yang Y, Koeffler HP, Taguchi H. HIV-1 protease inhibitor induces growth arrest and apoptosis of human multiple myeloma cells via inactivation of signal transducer and activator of transcription 3 and extracellular signal-regulated kinase 1/2. Mol Cancer Ther. 2004;3:473-479.

152. Pan J, Mott M, Xi B, et al. Phase I study of nelfinavir in liposarcoma. Cancer Chemother Pharmacol. 2012;70:791-799.

153. Wagner KD, Benchetrit M, Bianchini L, Michiels JF, Wagner N. Peroxisome proliferator-activated receptor $\beta / \delta(\operatorname{PAAR} \beta / \delta)$ is highly expressed in liposarcoma and promotes migration and proliferation. J Pathol. 2011;224(4):575-588.

154. Debrock G, Vanhentenrijk V, Sciot R, Debiec-Rychter M, Oyen R, Van Oosterom A. A phase II trial with rosiglitazone in liposarcoma patients. Br J Cancer. 2003;89:1409-1412.

155. Pishvaian MJ, Marshall JL, Wagner AJ, et al. A phase 1 study of efatutazone, an oral peroxisome proliferator-activated receptor gamma agonist, administered to patients with advanced malignancies. Cancer. 2012;118:5403-5413.

156. Manara MC, Nicoletti G, Zambelli D, et al. NVP-BEZ235 as a new therapeutic option for sarcomas. Clin Cancer Res. 2010;16(2):530-540.

157. Smith KB, Tran LM, Tam BM, et al. Novel dedifferentiated liposarcoma xenograft models reveal PTEN down-regulation as a malignant signature and response to PI3K pathway inhibition. Am J Pathol. 2013;182:1400-1411.

158. Schöffski P, Ray-Coquard IL, Cioffi A, et al; European Organisation for Research and Treatment of Cancer (EORTC) Soft Tissue and Bone Sarcoma Group (STBSG). Activity of eribulin mesylate in patients with soft-tissue sarcoma: a phase 2 study in four independent histological subtypes. Lancet Oncol. 2011;12:1045-1052.

159. Jemal A, Siegel R, Xu J, Ward E. Cancer statistics. CA Cancer J Clin. 2010;60:277-300.
OncoTargets and Therapy

\section{Publish your work in this journal}

OncoTargets and Therapy is an international, peer-reviewed, open access journal focusing on the pathological basis of all cancers, potential targets for therapy and treatment protocols employed to improve the management of cancer patients. The journal also focuses on the impact of management programs and new therapeutic agents and protocols on
Dovepress

patient perspectives such as quality of life, adherence and satisfaction The manuscript management system is completely online and includes a very quick and fair peer-review system, which is all easy to use. Visit http://www.dovepress.com/testimonials.php to read real quotes from published authors. 